\title{
Educação escolar e constituição do afetivo: algumas considerações a partir da Psicologia Histórico-Cultural
}

Cláudia Aparecida Valderramas Gomes*

Suely Amaral Mello**

\section{Resumo}

A Psicologia Histórico-Cultural afirma a tese da experiência social como base da formação humana e aponta a unidade afetivo-cognitiva como mediadora nas relaçôes do sujeito com o conhecimento no desenvolvimento das funções psicológicas. Este artigo apresenta alguns elementos que apontam para a constituição dos processos afetivos a partir das relaçôes que o sujeito mantém com as objetivaçóes humanas. Parte da crítica ao pensamento organicista e subjetivista que, tanto na Psicologia quanto na Educação, separa as emoções das demais funçóes no conjunto da consciência humana - tratando-as como um impeditivo nos processos de ensino e de aprendizagem escolar - e assinala a importância de se (re) pensar as relaçôes que o sujeito estabelece com a realidade, o papel do conhecimento e das condiçóes concretas de vida e de educaçáo que produzem os processos afetivos. Defende que pensamento e sentimento são processos psicológicos desenvolvidos a partir da história de apropriaçáo e objetivaçáo de signos e instrumentos que cada sujeito realiza, e afirma a educaçáo escolar e o caráter intencional do trabalho docente - na organização e conduçáo da prática pedagógica - como elementos determinantes na transformação dos modos de pensar e sentir.

Palavras-chave: Psicologia. Afeto (Psicologia).

* Doutora em Educação pela Universidade Estadual Paulista - Unesp-Marília. Professora do Departamento de Psicologia Evolutiva, Social e Escolar do Curso de Psicologia da UNESP - campus de Assis. Membro do grupo de Pesquisa Implicaçóes Pedagógicas da Teoria Histórico-Cultural da Unesp-Marília.

** Doutora em Educação pela Universidade Federal de São Carlos - Ufscar. Professora do Curso de Pós-Graduação em Educação da Faculdade de Filosofia e Ciências da Unesp - campus de Marília, vice-líder do grupo de pesquisa Implicações Pedagógicas da Teoria Histórico-Cultural e coordenadora do Grupo de Estudos em Educação Infantil do mesmo campus da Unesp. 


\section{Introdução}

Dar início à reflexão sobre a constituição do afetivo ${ }^{1}$ nos coloca diante de um desafio: transitar de uma compreensão biológica para uma compreensão histórica e social do psiquismo humano. Isso, que constitui uma dificuldade, é decorrência do modelo adotado pelas Ciências Humanas de modo geral, em particular pela Psicologia, que, ao enfatizar a separação entre corpo e mente, contribuiu significativamente para a priorizaçáo de um elemento em detrimento de outro.

$\mathrm{Na}$ esteira dessas concepçóes, a Psicologia tradicional estabeleceu outras dicotomias que, atualmente, parecem cristalizadas no terreno da educação escolar. Basta observarmos como afeto e cognição são tratados de forma independente no conjunto do psiquismo humano e como as explicaçóes sobre as emoçóes surgem sem nenhum tipo de relação com as outras formaçóes ou processos psicológicos.

Por meio dessa análise reducionista, afetos ou emoçóes aparecem como um elemento que pode ser definido e descrito em seus diferentes tipos de manifestação, identificado, muitas vezes, com um universo interno, intrapsíquico e como um fenômeno naturalmente presente no sujeito desde o nascimento e o qual vai se revelando à medida que este se desenvolve.

Essa maneira de compreender os processos afetivos tem como implicação pedagógica a adoção de uma visão homogênea e constante da motivação, em que as necessidades, os desejos e interesses das crianças que pressupóem processos afetivos - são tratados como aspectos inerentes à personalidade infantil, como um dado natural, portanto, independente da sua história de vida e do trabalho realizado na escola.

Nesse caso, a aprendizagem ou não dos conteúdos escolares, o avanço e a conquista do saber socialmente elaborado (tanto quanto a sua não-apropriação) pressupóem fundamentalmente que o sujeito disponha ou não dos recursos motivacionais para a aprendizagem, sugerindo um determinismo prévio na relaçáo do sujeito com os objetos do conhecimento.

O emocional aparece frequentemente associado a experiências vividas pela criança na sua primeira infância, a traços de personalidade ou à estrutura e dinâmica familiares que, ao interferir na aprendizagem, acabam "perturbando" seu desenvolvimento intelectual. Um equívoco ainda predominante na escola é pensar que as emoçóes são prejudiciais, 
um impeditivo que, por vezes, compromete o processo de escolarização das crianças e jovens.

Estão dadas as condiçóes para um desdobramento da dicotomia afetivo-cognitivo na interface da Psicologia com a Educação: a concepção subjetivista dos afetos. Tal concepção restringe as possibilidades de intervenção da educação escolar na formação do sujeito sob a alegação da dificuldade de acesso e impotência do educador no que tange aos processos afetivos, uma vez que, segundo a escola, esses processos se referem a outro domínio do comportamento humano - o emocional - e são acessíveis apenas ao psicólogo.

Essa tendência de relacionar fracassos na aprendizagem a problemas afetivos tem suscitado estudos na interface da Psicologia com a Educação levando alguns autores (COLLARES; MOYSÉS, 1996; MEIRA, 2003; PATTO, 1999, 2000; SOUZA, 1997, 2007) a problematizar a concepção corrente entre educadores e psicólogos de que problemas emocionais determinam o náo-aprendizado na escola.

A tentativa de explicação da natureza e constituição dos processos afetivos no conjunto do psiquismo humano se legitima a partir das categorias propostas pela Psicologia Histórico-Cultural, que pretende superar algumas dicotomias historicamente constituídas, demarcando o aporte teórico do materialismo histórico-dialético e as demais abordagens em Psicologia.

É desse ponto de vista teórico que este texto propóe uma reflexão acerca da constituição do afetivo e aponta para a função da educação escolar nesse processo, reconhecendo o cuidado metodológico de tratar processos afetivos e cognitivos como uma unidade dialética que permeia toda e qualquer relação do sujeito com o conhecimento, gênese da sua formação humana.

\section{A formação humana do sujeito e a constituição dos processos afetivos}

Para esclarecer como se dá a formação humana, é preciso adiantar que os homens se realizam por meio da história. Isso significa que é a partir das condiçóes concretas de vida que os seres humanos desenvolvem suas propriedades e qualidades humanas, e, nesse sentido, a formação do ser humano representa uma síntese da cultura produzida pela história humana. 
"O homem cria a história e vive na história já muito antes de conhecer a si mesmo como ser histórico" (KOSIK, 2002, p. 230).

Sendo assim, é importante pontuar dois aspectos intercondicionados que fundamentam o movimento da história. O primeiro, já mencionado, é o fato de que a história é criada pelo homem, e o segundo é a necessidade de que nessa criação exista uma continuidade (KOSIK, 2002, p. 238). A história só é possível uma vez que o homem não começa tudo sempre do princípio, mas o faz a partir dos resultados obtidos pelas geraçóes anteriores. Esse princípio legitima o fato de que o trabalho ou a atividade vital humana pressupóe uma continuidade.

Nesse caso, a maior parte dos conhecimentos e habilidades humanas de que o homem dispóe não advêm da sua própria experiência, mas são adquiridos por meio da apropriação da experiência acumulada pelas geraçóes passadas.

Essa atividade humana que o homem realiza e que, portanto, cria a história e o ser do homem é também denominada práxis, conceito da filosofia marxista que sintetiza as objetivaçóes humanas. Nas palavras de Kosik (2002, p. 224, grifos do original):

[...] a práxis compreende - além do momento laborativo - também o momento existencial: ela se manifesta tanto na atividade objetiva do homem, que transforma a natureza e marca com sentido humano os materiais naturais, como na formação da subjetividade humana, na qual os momentos existenciais como a angústia, a náusea, o medo, a alegria, o riso, a esperança etc., não se apresentam como "experiência" passiva, mas como parte da luta pelo reconhecimento, isto é, do processo da realização da liberdade humana.

Portanto, é a relação entre as objetivaçóes sociais - que existem como práxis objetivada - e o processo de apropriação, realizado pelos indivíduos singulares ${ }^{2}$, que engendra a formação de capacidades, motivos, habilidades, sentimentos, modos de pensar e de agir que, em síntese, configuram a existência psicológica ou a formação humana do sujeito.

Todavia, o modo como a Educação tem se referido aos processos afetivos denota um profundo desconhecimento acerca da natureza, 
constituição e participação desses processos afetivos na estrutura psicológica do sujeito. Isso advém da marca dualista que a filosofia de Descartes deixou na teoria do conhecimento (ESPINOSA, 2004; TEIXEIRA, 2001; VIGOTSKI, 1993). Tendo influenciado profundamente a história da Psicologia até hoje, insiste em considerar as emoçóes como rudimentos que precisam ser subordinados pelo racional-cognitivo (VIGOTSKI, 2004).

Assim, também, é a maneira como a Psicologia tradicional tem realizado o estudo das funções psíquicas (percepção, atenção, memória, pensamento, linguagem, sentimento), apreendendo-as isoladamente, explicando esses processos como algo que se desenvolve no embate entre o sujeito individual e a realidade social - baseada nos princípios da lógica formal.

Contrária a esse modelo de pensamento, a dialética se coloca para o materialismo histórico como o método capaz de apreender o movimento dos fenômenos e objetos da realidade - é a lógica da historicidade. $\mathrm{Ou}$ seja, diante da indagaçáo sobre como conhecer algo que muda o tempo todo, a dialética aparece como a possibilidade lógico-metodológica para a compreensão da historicidade humana que inclui, necessariamente, os processos psicológicos que se manifestam no indivíduo singular.

Para a Psicologia Histórico-Cultural, entender como se dá a constituição do afetivo significa pensar, necessariamente, num movimento ou numa transformação que esses processos sofrem ao longo do desenvolvimento humano, refletindo a especificidade e complexidade da formação humana do sujeito.

Vigotski (1995) oferece uma explicação dos fenômenos e processos a partir de sua história e interdependência e, coerente com a matriz dialética que fundamenta sua teoria, considera que as emoçóes sofrem mudanças qualitativas à medida que o sujeito avança no desenvolvimento das demais funções psíquicas.

Esse autor explica a indissociabilidade de cada função específica no desenvolvimento global da personalidade, enfatizando que, assim como ocorre com o desenvolvimento de outras funçóes psicológicas como a percepção, a memória, o pensamento e a linguagem, no que tange aos processos afetivos, também existem diferenças significativas quando comparamos a criança e o adulto. 
Essas mudanças qualitativas que ocorrem com as emoçóes ao longo do desenvolvimento, distanciando-as de sua origem biológica ao se constituírem como fenômeno histórico e cultural, representam uma conquista do sujeito: um maior controle sobre si mesmo, sobre sua própria conduta, determinado pelo crescente domínio de instrumentos culturais - signos e instrumentos -, dentre os quais se destaca a linguagem.

Nesse ponto de vista, as funçóes afetivas se colocam em relação direta com outras formações psicológicas e com o pleno desenvolvimento da consciência, já que o lugar social que o sujeito ocupa no interior das suas relaçóes, seu repertório cultural, suas experiências e interaçóes com outras pessoas representam fatores indispensáveis para compreender os processos envolvidos em seu desenvolvimento.

Como um dos inspiradores da teoria vigotskiana das emoçóes e referência na análise histórico-psicológica que Vigotski (2004) realiza acerca do afetivo, Espinosa ${ }^{3}$ (1632-1677) explica, em sua obra, a relação entre corpo e alma, bem como a natureza, a origem e a essência da alma, da razão e dos afetos, elementos indispensáveis para alcançarmos a compreensão da unidade afetivo-cognitivo segundo a Psicologia Histórico-Cultural. A inovação da filosofia espinosista consiste em romper com a ideia cartesiana da alma como uma substância dotada de um conjunto de funçóes ou faculdades autônomas como a imaginação, a memória, o pensamento, sentimento e a vontade, mas apreendê-la como o próprio conhecimento. Assim, Espinosa esforçou-se para provar que a alma existe, essencialmente, a partir da atividade de pensar o objeto. "Como a alma não é uma substância (anímica), a expressão uma percepção na alma só pode significar um estado de consciência” (ESPINOSA apud TEIXEIRA, 2001, p. 122, grifo do autor).

Para compreender a relação entre processos afetivos e cognitivos, devemos, primeiramente, analisá-la do ponto de vista da compreensão do psiquismo humano como um sistema funcional que correlaciona elementos biológicos, psicológicos e sociais, e que tem nas categorias de atividade e consciência seu núcleo de sustentação e desenvolvimento.

Também denominado reflexo psíquico da realidade (LEONTIEV, 1978), o psiquismo compreende um substrato material, orgânico e natural como ponto de partida. Isso significa que o desenvolvimento do sujeito principia pelas funçóes psíquicas elementares, dado que o aproxima dos animais no início da ontogênese. 
O materialismo histórico-dialético parte, antes de tudo, da teoria do reflexo - reconhecendo o fato de que as ideias do sujeito refletem os objetos da realidade. Ou seja, no conceito de reflexo está o pressuposto da existência das coisas, processos e fenômenos da realidade objetiva fora e independentemente da consciência humana, que é refletida de modo criativo pelo sujeito no momento do conhecimento.

Esse reflexo psíquico da realidade é consciente. É por meio da consciência que nos localizamos e nos orientamos na realidade; nossa relação com o meio é mediada pela consciência. Porém, entendê-la como um atributo e dimensão intrínseca do nosso psiquismo implica considerar seu desenvolvimento de forma processual e contínua. Não se trata de compreender a consciência como um dado a priori ou "algo que já está dentro" do sujeito, e sim como um produto de sua atividade no mundo objetivo.

Graças à complexificação de sua atividade, o homem vai lidando com os objetos e fenômenos da realidade como objetos alheios a ele e, nesse processo, vai estruturando sua consciência, desenvolvendo-a a partir das condiçóes sociais e culturais concretas em que está situado. Conforme Leontiev (1978, p. 66), é na atividade onde se realizam as transiçóes recíprocas entre os polos "sujeito-objeto", uma vez que, por meio da atividade, o objeto transita para sua imagem subjetiva, e, nesse mesmo processo, acontece a impressáo do trabalho humano sob a forma de resultados objetivos, de produtos externos que carregam em si as marcas da atividade humana. Nas palavras de Marx (apud LEONTIEV, 1978, p. 66), "Na produção se objetiviza a personalidade; no consumo se subjetiviza o objeto".

A filosofia de Espinosa explica que a consciência - denominada no século XVII como alma - surge a partir da vivência e/ou experiência pelo sujeito de uma afecção (affectio), que é a ação de outro corpo qualquer sobre o seu.

Assim, se uma afecção representa as açóes dos outros corpos e ideias sobre o ser humano determinando a possibilidade do conhecimento, e se a consciência é, por definição, um sistema de conhecimentos - conforme Marx (1993, p. 252): "o modo como a consciência é e como algo para ela existe é o conhecer”, o nível de consciência do sujeito dependerá das afecçóes ou de como o sujeito é afetado e percebe os objetos. 
Afeto diz respeito àquilo que afeta, o que mobiliza, por isso reporta a sensibilidade, sensaçóes. Podemos ainda referir afeto como ser tomado por, atravessado, perpassado, quer dizer: afetado. Este atravessar, perpassar é o que propriamente dá o caráter de afecção.

Quando o sujeito experiencia uma afecção, essa vivência provoca nele uma alteração da sua potência de pensar, sentir e agir. Em relação a isso, é importante dizer que potência não pode ser confundida com possibilidade, pré-formação, predeterminação ou preexistência, mas deve ser apreendida como um esforço - uma atitude em relação ao objeto - que o sujeito realiza e que se manifesta, diferentemente, segundo os objetos encontrados.

Do efeito decorrente do encontro de algum objeto - corpo, fenômeno ou ideia - com o nosso corpo, emerge um sentimento de variação da nossa capacidade de pensar, de agir, sentir e de aprender.

Assim, o afeto (affectus) pode ser definido, segundo a teoria de Espinosa, como um "regime de variação" (DELEUZE, [1978]) que acontece à medida que as ideias vão se afirmando em nós, durante nossa existência diária, ou à medida que vamos experienciando acontecimentos.

Essa flutuação das potências de agir e de pensar, ora podendo elevar-se - determinando um estado de alegria -, ora podendo diminuir - no estado de tristeza -, dependem do modo como se dá a relação entre sujeito e afecçôes.

Determinado pela experiência da afecção, o desejo mobiliza ou movimenta nossa potência de vida. Assim, se o esforço (ou potência) é uma expressão do desejo, este desejo nos motiva a agir diferentemente segundo os objetos que encontramos. Portanto, devemos concluir que o desejo está, a cada instante, determinado pelas afecçóes (efeitos) que nos vêm dos objetos. Nesse caso, é preciso dizer que as afecçóes determinam as possibilidades do conhecimento pelo sujeito.

A consciência emerge consequentemente como o sentimento contínuo dessas variaçôes em função da relação que se estabelece entre sujeito e objeto. Para a Psicologia de Vigotski, a relação entre sujeito e objeto é a base sobre a qual se constitui o reflexo psíquico da realidade. Do mesmo modo, o tratamento dispensado por Espinosa às afecçóes e aos afetos também nos remete a essa mesma relação, já que, segundo esse filósofo, a afecção pressupõe a ação de um objeto qualquer sobre o sujeito, enquanto o afeto - indutor da potência de agir - indica a ação do sujeito sobre o objeto. 
Essa relação é o que caracteriza o primado do desenvolvimento da consciência para a Psicologia Histórico-Cultural, que, por esse mesmo motivo, reafirma o papel determinante que os mediadores sociais exercem na constituição das funçóes psicológicas superiores, as quais só se concretizam mediante a atividade social do sujeito.

Daí nossa preocupação em apontar para o papel da educação escolar como mediadora na superação das formas primitivas de comportamento em direção às formas mais sofisticadas e complexas de apropriação dos objetos culturais.

Tratar o reflexo psíquico como efeito da relação entre sujeito e objeto implica que a imagem subjetiva de um dado objeto exige que este se coloque como objeto para um dado sujeito. É nessa trama que se dá a complexidade do processo de apropriação-objetivação pelo sujeito e que se constituem as funçóes cognitivas e as funções afetivas, caracterizando o desenvolvimento da sua consciência.

A distinção dessas funções psicológicas no psiquismo permite concluir que as funçóes cognitivas constroem a imagem subjetiva do objeto em sua concretude, e as funçóes afetivas, igualmente, cumprem a representação do objeto, porém, constroem a imagem da relação do sujeito com aquele objeto. Portanto, o pensamento e os sentimentos são processos psicológicos desenvolvidos pelo homem na sua relação com o mundo.

"A unidade afetivo-cognitiva é mediadora constante nas atividades realizadas pelo indivíduo ao longo de sua vida, portanto, tudo que a constitui é, ao mesmo tempo, objeto do pensamento e fonte de sentimentos" (MARTINS, 2007, p. 129).

Já que a função cognoscitiva da consciência se caracteriza pela sua interconexão com a atividade, esse fenômeno que articula processos cognitivos e afetivos determinando a formação da consciência e sua objetivação, sob a forma de atividade humana, aponta para o sentido como uma categoria que sintetiza o sentir, o pensar e o fazer.

González Rey (2003, p. 249) analisa a integração do afetivo na vida psíquica como um processo pelo qual o afeto ganha sentido subjetivo. Para ele: "Uma experiência ou ação só tem sentido quando é portadora de uma carga emocional".

Conforme o autor, a emoção caracteriza o estado do sujeito ante toda a ação, ou seja, as emoçóes estão estreitamente associadas às ações que 
o indivíduo realiza no conjunto das suas relações sociais. A emoção é que define a disposiçáo do sujeito para atuar ou ainda, conforme Espinosa, o sentimento de variação traduzido pela elevação ou diminuição das potências de pensar e agir é que determina a orientação do sujeito para esta ou aquela direção, indicando sua atividade ou passividade.

Se consideramos o afetivo em sua condição subjetiva, sem perder de vista o modo como o interno e o externo se articulam de forma a permitir sua formação, fica ainda por explicar: qual é a condição interna do sujeito que se faz sensível ao registro emocional?

A necessidade surge como essa condição - ela é o estado emocional do sujeito que é gerado de forma constante no curso de suas atividades. Toda atividade ou relaçáo, para ter sentido para o sujeito, implica o surgimento de um conjunto de necessidades. Entretanto, esse sentido se dá no contexto da realização dessa ação (GONZÁLEZ REY, 2003, p. 245).

$\mathrm{O}$ mecanismo produtor de necessidades ou desejos pressupóe a criação de situaçóes nas quais haja afetação, ou seja, se o conhecimento é efeito de afecçóes, importa produzir encontros que sejam meios de afetar positivamente, criando maneiras e relaçóes que potencializem o pensar e o agir dos sujeitos afetados.

Nesse processo, o sentido aparece como expressão de uma nova síntese, que acontece no movimento permanente dos significados e dos afetos experienciados - a unidade afetivo-cognitiva. $\mathrm{O}$ sentido caracteriza-se por aquela qualidade que a significação social adquire para o sujeito, a partir da sua vivência e experiência.

Quando o sujeito se depara com as objetivaçóes sociais - que detêm a qualidade de conhecimentos universais passíveis de serem compartilhados -, desse encontro, que afeta, poderá emergir ou não um desejo ou a necessidade de conhecer ou apropriar-se desse objeto social. Entretanto, a apropriação desse conteúdo dependerá do emprego ou mobilização, pelo sujeito, de um esforço capaz de reproduzir para si as características postas nesse objeto social.

Mediado pela apropriação do significado/função social do objeto, esse conteúdo é objetivado por meio da atividade realizada pelo sujeito, resultando desse processo o sentido pessoal como uma síntese do social e do individual, do objetivo e do subjetivo, do cognitivo e afetivo, na qualidade de uma experiência psicológica, vinculada aos desejos e necessidades do 
sujeito, àquilo que ele experimentou na vivência das afecções. É desse modo que Leontiev (1978) afirma que os significados sociais não existem de outro modo que não seja realizando uns e outros sentidos pessoais.

\section{A educação escolar e a unidade afetivo-congnitivo: algumas implicações}

As consideraçóes sobre a constituição do afetivo no desenvolvimento do sujeito não cabem em um único artigo. Neste caso, coube-nos apenas apontar alguns elementos que entendemos necessários para superar equívocos que ainda perduram quando se trata desses processos humanos.

Em primeiro lugar, devemos pontuar como um equívoco o fato de se analisar o afetivo como algo que se acrescenta ao cognitivo, como um elemento ou pré-formação da psique que segue ao lado, permitindo ou impedindo que o sujeito conquiste os conhecimentos e avance os limites do seu desenvolvimento. Isso nos apresenta o desafio de entender as funçóes afetivas acontecendo na processualidade das açóes do sujeito.

Conforme Vigotski, na quarta conferência sobre as bases da pedologia ${ }^{4}$, ao tratar do papel da influência do meio cultural sobre o desenvolvimento infantil, precisamos considerar a forma como a criança se relaciona com esse meio. Nas palavras do autor,

[...] deve-se considerar o meio não como uma circunstância do desenvolvimento, por encerrar em si certas qualidades ou determinadas características que já propiciam, por si próprias, o desenvolvimento da criança. É sempre necessário abordá-lo a partir da perspectiva de qual relação existe entre a criança e o meio em dada etapa do desenvolvimento. (VIGOTSKI, 1994, p. 338, grifos nossos).

A relação que se estabelece entre a criança e a cultura é sintetizada por Vigotski no conceito de vivência como uma unidade de elementos do meio e de elementos da personalidade, como unidade do subjetivo e do objetivo, como a unidade sujeito/cultura. Para ele, a análise do papel do meio no desenvolvimento da criança deve ser conduzida "do ponto de vista das vivências da criança”, considerando que, conforme o texto, 
A vivência é uma unidade na qual, por um lado, de modo indivisível, o meio, aquilo que se vivencia está representado - a vivência sempre se liga àquilo que está localizado fora da pessoa e, por outro lado, está representado como eu vivencio isso, ou seja, todas as particularidades da personalidade e todas as particularidades do meio são apresentadas na vivência, tanto aquilo que é retirado do meio, todos os elementos que possuem relaçáo com dada personalidade, como aquilo que é retirado da personalidade, todos os traços de seu caráter, traços constitucionais que possuem relação com dado acontecimento. Desta forma, na vivência, nós sempre lidamos com a uniáo indivisível das particularidades da personalidade e das particularidades da situaçáo representada na vivência. (VIGOTSKI, 1994, p. 342, grifos no texto original).

Desse ponto de vista, para analisar a influência de um dado fato ou situação no desenvolvimento da criança, não basta tomar esse fato independentemente da criança. É preciso perceber como esse fato é interpretado em sua vivência.

Ainda segundo o autor, cada situação - em que a criança se relaciona com o meio - mobiliza algumas e não todas as peculiaridades da criança. Isso significa dizer que, em cada situação, algumas peculiaridades exercem papel principal, enquanto outras podem estar ausentes. Sendo assim, para compreender a influência do meio sobre o desenvolvimento da criança, “[...] é importante saber quais dessas peculiaridades constitucionais desempenham um papel determinante para definir a atitude da criança frente a dada situaçáo" (VIGOTSKI, 1994, p. 342, grifos no texto original). Por isso, vale insistir, a análise do papel do meio no desenvolvimento da criança deve ser conduzida "do ponto de vista das vivências da criança".

Com essa discussão, ao destacar o papel mediador da vivência na relação entre criança e cultura, Vigotski destaca a unidade do cognitivo e do afetivo - o lugar da emoção e das "particularidades da personalidade" no processo de se relacionar com a cultura e aprender - que, do nosso ponto de vista, revoluciona a compreensão que o/a professor/a tem do processo 
de aprendizagem e, consequentemente, revoluciona a forma de pensar e propor o ensino.

Outra implicaçáo pedagógica de se pensar o afetivo como determinado pelo conhecimento dos objetos, pelas relaçóes e condiçóes objetivas de vida e de educação - e não como algo natural, interno e a-histórico, descolado das relaçôes vivas e dinâmicas que o sujeito estabelece com a socialidade diz respeito à observação do lugar que a criança ocupa nas relaçóes que se estabelecem na escola e como a ela se dirigem as práticas educativas.

Ultrapassar a visão natural e subjetivista dos afetos significa reconhecer que o conhecimento é alicerçado pelo desejo e que ninguém deseja alguma coisa sem antes ter dela alguma noçáo. Consequentemente, pensar na motivação para a aprendizagem implica pensar em afetação, em como o sujeito é tomado por, atravessado, perpassado pelas ideias, pelos objetos e fenômenos da realidade escolar.

Conforme Leontiev (1978, p. 228), em meio à complexidade que envolve a relaçáo da criança com a cultura na escola $-\mathrm{e}$, consequentemente, o processo de aprendizagem e de humanizaçấo -, a questáo mais simples diz respeito à " $[. .$.$] dependência existente entre o êxito do estudo e o sentido que$ tem para a criança aquilo que estuda”. Essa constatação leva o autor a afirmar que "[...] a aprendizagem, os conhecimentos que se adquire, educam, e isso não se deve subestimar. Mas para que os conhecimentos eduquem, é preciso educar a atitude frente aos conhecimentos" (LEONTIEV, 1978, p. 234).

Tudo isso sugere indagaçôes sobre como se estabelecem as relaçôes no dia-a-dia da escola. Como se organizam as atividades? Sob a direçấo de uma única pessoa, no caso o professor, ou de forma a garantir a participaçáo do coletivo na sua condução? Como se distribui o tempo no cotidiano escolar? Ocupando-o com tarefas que massificam ou, ao contrário, contemplando o exercício pleno de todas as funçôes humanas? Como se elegem os conteúdos a serem trabalhados? Adotando um referencial pronto carregado de conteúdo ideológico que mascara relaçóes de poder e dominação ou possibilitando o exercício reflexivo acerca da condição humana numa sociedade desigual?

Essas indagaçóes nos encaminham para a natureza e o papel da mediação na apropriaçáo do conhecimento que, na escola, se caracteriza, fundamentalmente, pelo lugar ocupado pelo professor. Mediando a relação da criança com o conhecimento está o adulto, e, portanto, cabe a ele um 
importante papel na criação intencional de situações que promovam necessidades e desejo de conhecimento.

Esse é o caráter histórico dos afetos. Eles são decorrentes de efeitos que nos vêm dos objetos, acontecimentos e relaçóes com os quais nos deparamos durante a nossa existência diária. Isso é o que mobiliza nosso esforço ou a nossa atitude diante dos objetos sociais dando origem à ação e à atividade, e que possibilita pensar a motivação humana como algo emergindo a partir da atividade realizada pelo sujeito num processo histórico, que se integra nos diferentes momentos da sua atividade e é extremamente variável, rompendo com a visão constante e homogênea da motivação.

Com esse novo olhar, resultante da superação da fragmentação entre afetivo e cognitivo, deixamos de pensar as experiências afetivas como algo que acontece fora da escola, superamos a atitude que elege o cognitivo como única preocupação da atuação escolar e passamos a considerar como elemento essencial do processo educativo as funçóes psíquicas que conformam a personalidade humana.

Quando a escola postula os processos afetivos como alguma coisa do sujeito, apenas, como um fenômeno natural e descolado das relaçóes concretas que o sujeito experiencia na situação escolar, ela individualiza o processo educativo, centrando apenas no aluno as condiçóes de aprendizagem e desenvolvimento, e desconsiderando a força das relaçóes humanas na produção do sentido que a aprendizagem escolar adquire para o sujeito.

Nesse caso, a escola exige um espaço dedicado à reflexão sobre como promover o desenvolvimento integral da criança, entendendo que os conteúdos apresentados, tanto quanto as relaçóes humanas ali estabelecidas, estarão afetando positiva ou negativamente as consciências das crianças. Ponto de partida para a constituição de uma escola humanizadora é a compreensão de que náo se promove o desenvolvimento de processos cognitivos independentemente de processos afetivos - os quais são o começo e o fim de toda a aprendizagem e de todo o desenvolvimento humano.

\section{Notas}

1 O adjetivo "afetivo" está sendo empregado neste texto conforme a atribuição filosófica, que designa em geral tudo o que se refere à esfera das emoçóes: estado, função ou condição de caráter genericamente emotivo, 
podendo referir-se a qualquer emoção, afeto ou paixão (ABBAGNANO, 2007, p. 20).

2 Sobre a análise deste processo, ver Duarte (1993), que apresenta uma teoria sobre a formação histórica da individualidade no livro $A$ individualidade para-si: contribuição a uma teoria histórico-social da formação do individuo. Campinas: Autores Associados, 1993.

3 Para o aprofundamento dessa discussão, consultar Gomes (2008).

4 Essa conferência, intitulada $O$ problema do meio na Pedologia, publicada pela Editora do Instituto Pedagógico de Leningrado em 1935, estará em breve disponível em português em dossiê especial da Revista de Psicologia da USP organizado por Gisele Toassa.

\section{REFERÊNCIAS}

ABBAGNANO, N. Dicionário de Filosofia. 5. ed. São Paulo: Martins Fontes, 2007.

COLlARES, C. A. L.; MOYSÉS, M. A. A. Preconceitos no cotidiano escolar: ensino e medicalização. São Paulo: Cortez, 1996.

DELEUZE, G. Espinosa em 24/01/78. In: DELEUZE, Gilles. Les cours de. [S.l.:s.n., 1978]. Disponível em: <http: www.webdeleuze.com>. Acesso em: 26 nov. 2010.

DUARTE, N. A individualidade para-si: contribuição a uma teoria histórico-social da formação do indivíduo. Campinas: Autores Associados, 1993.

ESPINOSA, B. Ética demonstrada à maneira dos geômetras. In: OS PENSADORES. São Paulo: Nova Cultural, 2004.

GOMES, C. A. V. O afetivo para a psicologia histórico-cultural: consideraçóes sobre o papel da educação escolar. 2008. Tese (Doutorado em Educação) - Faculdade de Filosofia e Ciências, Universidade Estadual Paulista, Marília.

GONZÁLEZ REY, F. L. Sujeito e subjetividade. São Paulo: Pioneira Thomson Learning, 2003. 
KOSIK, K. A dialética do concreto. Rio de Janeiro: Paz e Terra, 2002.

LEONTIEV, A. Actividad, conciencia y personalidad. Buenos Aires:

Ciencias del Hombre, 1978.

MARTINS, L. M. Algumas reflexóes sobre o desenvolvimento omnilateral dos educandos. In: MEIRA, M. E. M.; FACCI, M. G. D. (Org.). Psicologia histórico-cultural: contribuiçóes para o encontro entre a subjetividade e a educação. São Paulo: Casa do Psicólogo, 2007. p. 117134.

MARX, K. Manuscritos econômico-filosóficos. Tradução Artur Morão. Lisboa: Ed. 70, 1993.

MEIRA, M. E. M.; ANTUNES, M. A. (Org.). Psicologia escolar: teorias críticas. São Paulo: Casa do Psicólogo, 2003.

PATTO, M. H. S. A produção do fracasso escolar: histórias de submissão e rebeldia. São Paulo: Casa do Psicólogo, 1999.

. Mutaçóes do cativeiro: escritos de Psicologia e política. São Paulo: Hacker editores/Edusp, 2000.

SOUZA, M. P. R. A queixa escolar e o predomínio de uma visão de mundo. In: MACHADO, A. M.; SOUZA, M. P. R. (Org.). Psicologia escolar: em busca de novos rumos. São Paulo: Casa do Psicólogo, 1997. p. 17-33.

SOUZA, M. P. R. Prontuários revelando os bastidores: do atendimento psicológico à queixa escolar. In: SOUZA, B. P. (Org.). Orientação à queixa escolar. São Paulo: Casa do Psicólogo, 2007. p. 27-58.

TEIXEIRA, L. A doutrina dos modos de percepção e o conceito de abstração na filosofia de Espinosa. São Paulo: Editora Unesp, 2001.

VIGOTSKI, L. S. Obras escogidas II. Madrid: Visor, 1993.

. Obras escogidas III. Madrid: Visor, 1995.

. O problema do meio. In: VAN DER VEER, R.; VALSINER, J. (Org.). The Vygotsky Reader. Oxford: Blackwell, 1994.

. Teoría de las emociones: estudio histórico-psicológico. Madrid: Ediciones Akal, 2004. 


\section{Scholar education and affective constitution: Some considerations from Cultural-Historical Psychology}

\begin{abstract}
Cultural-Historical Psychology alleges the thesis of social experience as the basis of human formation and points the affective-cognitive unity as the intermediate in subject relations with the knowledge on the development of psychological functions. This article presents some elements that indicate the constitution of affective processes from the relations the subject maintains with human objectifications. Part of the critics to the organismic and subjectivist thought that, both in Psychology and in Education, separates
\end{abstract} emotions from other functions of human consciousness - treating them as deterrents in the teaching and school learning processes - and signs the importance of (re) thinking the relations the subject establishes with reality, the role of knowledge and of the concrete conditions of life and education that produce the affective processes. It defends that thinking and feeling are psychological processes developed from history of appropriation and objectification of signs and instruments that each subject realizes and affirms in scholar education, and the intentional character of teaching - in the organizational and

\section{Educación escolar \\ y la constitución de \\ lo afectivo: algunas \\ consideraciones a partir de la psicología-histórico cultural}

\section{Resumen}

La psicología Histórico-Cultural afirma la tesis de la experiencia social como base de la formación humana y apunta la unidad afectivo - cognitiva como mediadora en las relaciones del sujeto con el conocimiento en el desarrollo de las funciones psicológicas. Este artículo presenta algunos elementos que indican para la constitución de los procesos afectivos a partir de las relaciones que el sujeto mantiene con las objetivaciones humanas. Parte de la crítica al pensamiento organicista y subjetivista que tanto para la psicología como para la educación, separa la emociones de las demás funciones en el conjunto de la consciencia humana, tratándolas como un impedimento en los procesos de enseñanza y aprendizaje escolar, y señala la importancia de re-pensar las relaciones que el sujeto establece con la realidad, el papel del conocimiento y las condiciones concretas de vida y de educación que producen los procesos afectivos. Defiende que pensamiento y sentimiento son procesos psicológicos desarrollados a partir de la historia de la apropiación y objetivación de signos e instrumentos que cada sujeto realiza y afirma la educación escolar y el carácter 
pedagogical practice - as determinant intencional del trabajo docente - en elements in the transformation of the la organización y conducción de la ways of thinking and feeling.

Keywords: Psychology. Affection determinantes en la transformación de (Psychology).

los modos de pensar y sentir.

Palabras clave: Psicologia. Afecto.

\section{Cláudia Aparecida Valderramas Gomes}

Rua Antonio do Espírito Santo n. 8-18 - Paraíso

Bauru - SP - CEP: 17051-180

E-mail: cabegomes@uol.com.br

\section{Suely Amaral Mello}

Rua Rosalino Belline, 254 - Jardim Santa Paula

13564-050 São Carlos/SP

E-mail: suepedro@terra.com.br 